\title{
Evaluating Health Effects of Pulp and Paper Air Pollution in Webuye and its Environs in Kenya
}

\author{
Elvis K. Kiano (Corresponding author) \\ School of Environmental Studies, University of Eldoret, Kenya \\ E-mail: ekiano@yahoo.com \\ Wilson K. Yabann \\ School of Environmental Studies, University of Eldoret, Kenya
}

Joel Sumukwo

School of Environmental Studies, University of Eldoret, Kenya

Received: January 24, 2018 Accepted: February 6, 2018

doi:10.5296/emsd.v7i2.12817 URL: https://doi.org/10.5296/emsd.v7i2.12817

\begin{abstract}
Air pollution is a severe health issue having both morbidity and mortality effects to human beings. Pulp and paper milling characteristically emits many pollutants key among them Particulate Matter (PM) which is a lethal pollutant irrespective of the particulate diameter. Evidence shows that breathing air containing PM aggravates respiratory and cardiac mortality and morbidity, while precipitating adverse respiratory health outcomes such as asthma, lung function decline, lung cancer, and chronic obstructive pulmonary disease. This study sought to provide empirical evidence on health morbidity effects occasioned by $\mathrm{PM}_{10}$ of pulp and paper milling as a single source pollutant to a rural population in a developing country such as Kenya. This evidence includes prevalence of respiratory symptoms and relationship between exposure to pollutant and morbidity (sickness events). This was achieved through observational population-based cohort study. The study found positive association between $\mathrm{PM}_{10}$ concentration and prevalence of respiratory symptoms. The study found that a marginal increase of $\mathrm{PM}_{10}$ occasions a $12 \%$ increase in persistent cough prevalence. Similarly, common cold increased by $92 \%$ while wheezing increased by $22 \%$ all other factors remaining constant. the study concludes that Webuye environs exhibits high prevalence of respiratory diseases. Regarding morbidity effect of ambient air pollution, the study concludes that there
\end{abstract}


is a positive significant relationship between chronic exposure to $\mathrm{PM}_{10}$ and respiratory symptoms.

Keywords: Morbidity effects, Ambient air pollution, Particulate matter, Respiratory symptoms

\section{Introduction}

Air pollution became a health issue following the Meuse Valley fog in 1930 (Firket, 1936) and the London smog in 1952 that killed an estimated 4000 people. Air pollution is today regarded as an important research driver for a global public health protection (WHO, 2005). In fact, a high-level contact with pollution may it be long or short-term severe health effects and in extreme cases death.

Health effects results from long-term or short term exposure to the pollutant. Irrespective of the length of exposure, the effects may be acute or mild. Deaths or mortality was observed occasioned by pollution in London in 1952 the smog episode having lasted for only five days. While there is limited empirical evidence on health effects localised to pulp and paper pollution, there are several studies that relate to similar industrial processes that this study may relate to.

Morbidity effects have been observed as either cardiovascular (relating to the heart and circulation system) or respiratory. Kim et al (2015); Hoek et al (2013); Egondi, et al (2013) Olmo et al (2011) among others have found positive relationship between long-term or short term pollution exposure to cardio-respiratory diseases such as asthma and common cold. Karakis et al (2009) found Life Prevalence (LP) of upper respiratory tract chronic diseases (URTCD) and asthma in children aged 0-14 years living in rural Negev, Israel, in small agricultural communities to be associated with indirect measurements of exposure (distance, wind direction and odour complaints) to Industrial Park emissions located in the neighbourhood.

Similarly, though high respiratory infections among children were found to be attributable to poor nutrition and poverty levels in Vietnam by Le et al (2012), also find that short term exposure to pollutants such as nitrogen oxide, sulphur dioxide or particulate matter for periods not exceeding increased the likelihood of admission of children suffering from acute lower respiratory infection (ALRI)among others. Zúñiga et al (2016) conjectured an association between the air pollution and an increase in cardiovascular, respiratory, and diabetes mortality.

Over and above incidences of disease and its prevalence, air pollution has been indicated to cause strain on health resources available for dealing with other forms of diseases. Wordley, Walters and Ayres (1997); Ljungman \& Mittleman (2014) Donaldson \& Wedzicha (2014) and Nakhlé et al (2015); found significant associations between all respiratory admissions, cerebrovascular admissions, and bronchitis admissions and Particulate Matter $\left(\mathrm{PM}_{10}\right)$ when exposure occurs on the same day or over a period normally not exceeding a week. Over and above admission, emergency room (ER) visit were also seen to be excercabated by increase in level of pollutant in many cities across the globe. 
Whereas pollutants are varied in characteristics and emission sources, several epidemiologic studies continue to show Particulate Matter (PM) irrespective of the particulate diameter is a lethal pollutant. In fact empirical evidence shows that breathing air containing PM aggravates respiratory and cardiac mortality and morbidity, while precipitating adverse respiratory health outcomes such as asthma, lung function decline, lung cancer, and chronic obstructive pulmonary disease (Ayres et al., 2008; Ristovski et al., 2012).

In a study carried out in four large Asian cities, namely Bangkok, in Thailand, and Hong Kong, Shanghai, and Wuhan, in China, Wong et al, (2010) found the magnitude of the effects for cardiovascular and respiratory mortality to be generally higher than for all natural mortality at all ages. They also report that effects associated with $\mathrm{PM}_{10}$ in all natural, cardiovascular; and respiratory mortality were found to be higher in Bangkok than in the three Chinese cities. The explanation for these three findings might be related to consistently higher daily mean temperatures in Bangkok, variations in average time spent outdoors by the susceptible populations, and the fact that less air conditioning is available and used in Bangkok than in the other cities since $\mathrm{PM}_{10}$ concentrations were much higher in Bangkok. Similar findings are observed in multicities in Latin America by Romieu et al (2012).

Since there are numerous emissions in pulp and paper milling over and above PM, even as evidenced by Kiano et al (2017) this study sought to provide empirical evidence on health effects occasioned by all the $\mathrm{PM}_{10}$ of pulp and paper milling as a single source pollutant to a rural population in a developing country such as Kenya. This evidence includes prevalence of respiratory symptoms and relationship between exposure to pollutant and morbidity (sickness events).

\section{Literature Review}

\subsection{Determining Pollution Exposure Effects on Human Health: Exposure Characteristics}

When human beings interact with the environment, depending on the nature and levels of ambience, they are bound to be exposed to pollutants. Exposure can be one off depending on the contact with pollutant or several times across a span of time. In effect total daily exposure of an individual to air pollution is the sum of the separate contacts to air pollution experienced by that individual as he passes through a series of environments (also called micro-environments) during the course of the day (e.g. at home, while commuting, in the streets, etc.). Exposures in each of these environments can be estimated as the product of the concentration of the pollutant in question and the time spent in the environment.

Indoor air pollutants usually differ in type and concentration from outdoor air pollutants. Indoor pollutants include environmental tobacco smoke, biological particles, non-biological particles, volatile organic compounds, nitrogen oxides, lead, radon, carbon monoxide, asbestos, various synthetic chemicals and others. Degradation of indoor air quality has been associated with a range of health effects, from discomfort and irritation to chronic pathologies and cancers.

Altitude, temperature and humidity vary significantly across the globe. Brasseur, et al (2009) observes that at increased altitude the partial pressure of oxygen falls and inhalation increases 
in compensation. On the other hand, Le et al (2012) established that of the respiratory related admissions occurring within the study period, $60 \%$ occurred in the rainy season. This means that high humidity present during the rainy season does precipitate inhalation of pollutants. Thurston et al, (1994) also found that respiratory hospital admissions increased by $21 \%$ due to summertime haze air pollution in Toronto and Ontario. Brunekreef and Holgate (2002) have also observed that studies are now focusing more on weather-driven, variations in air pollution for especially due to the fact that air pollution high concentrations are prevalent during warm and sunny weather.

The age structure of populations differs markedly from country to country. Old people tend to show increased susceptibility to air pollution. As such Dominici et al (2006) indicate that elderly persons health is threated by airborne particles pollution and proceed to advice that national pollution standard should take this into consideration. The risk to older persons is aggravated because of the gradual weakening in physiological processes over time (U.S. EPA 2006). On the other hand, young children may also be at increased risk. For instance, studies by Patankar and Trivedi (2011) showed that children attending schools located proximate to the pollution sites were more likely to suffer certain air pollution related health conditions than their counterparts in different environments. Again this risk is attributed to the fact that children spend most of their active time outdoors yet have little volume per unit body weight, which could mean an increased PM dose per lung surface area and adverse effects on the developing lungs (U.S. EPA 2004). Whereas this study limited its interaction with household heads, it is not lost to the realisation the burden of disease in the household may arise from the affliction of any member

Likewise, people with a poor standard of living are bound to feel more the effects of pollution. This is because they tend to suffer from nutritional deficiencies, infectious disease due to poor sanitation Le et al, (2012; WHO (2004) and overcrowding, coupled with poor standard of medical care. Each of these factors may render individuals more susceptible to the effects of air pollution. Diseases which produce narrowing of the airways, a reduction in the area of the gas-exchange surface of the lung and an increased alteration of inhalation-perfusion ratios are likely to make the subject more susceptible to the effects of a range of air pollutants.

Carlsen, (2014) notes that the adverse effects from exposure to air pollution can be more severe in susceptible individuals. These are often considered to be the very old and very young, or individuals with a pre-existing condition which makes them more sensitive to exposure to air pollution. Susceptibility may also be brought about by individual habits such as smoking. Susceptibility notwithstanding it is important to acknowledge that continued exposure will lead to otherwise healthy individuals becoming sick and hence susceptible, thus one thing leads to another.

\subsection{Effect of Pollution Exposure on Human Health}

The main effects of air pollution on the body are found in the cardiopulmonary (relating to the heart and lungs) system. As a person breathes in a polluted atmosphere the functioning of the lungs and the entire system is impaired. This could leave the body without the required amount of oxygen in the short term. If the conditions persist them episodes of illness 
(morbidity) may arise leading to hospital visits or admission. Conversely in severe circumstances, the subject may suffer death.

While it has been illustrated in the preceding review a host of pollutant which plague ambient air quality, from a perspective of effect on human health, this study concentrated on particulate matter. On the other hand, while morbidity and mortality are feasible end point when it comes to pollution health effects, the study chose to limit its scope to morbidity since it measurement is more plausible in its various instances unlike mortality which is final and may be confounding. The study moves to consider exactly that in this proceeding section.

\subsubsection{Morbidity Effect of Particulate Matter $\left(\mathrm{PM}_{10}\right)$ on Human Health}

Particulate matter has been confirmed to affect more people than any other pollutant (Harrison \& Yin, 2000). The major components of PM are sulphate, nitrates, ammonia, sodium chloride, black carbon, mineral dust and water. It consists of a complex mixture of solid and liquid particles of organic and inorganic substances suspended in the air. The most health-damaging particles are those with a diameter of 10 microns or less, $\left(\leq \mathrm{PM}_{10}\right)$, which can penetrate and lodge deep inside the lungs. Long-lasting exposure to particles contributes to the risk of developing cardiovascular and respiratory diseases, as well as of lung cancer (Kim, Kabir \& Kabir 2015)

Air quality measurements are typically reported in studies in terms of daily or annual mean concentrations of PM10 particles per cubic meter of air volume (m3) (Esworthy, 2013). He also affirms that routine air quality measurements typically describe such PM concentrations in terms of micrograms per cubic meter $(\mu \mathrm{g} / \mathrm{m} 3)$ When sufficiently sensitive measurement tools are available, concentrations of fine particles $\left(\mathrm{PM}_{2.5}\right.$ or smaller) are also reported and applied in studies.

Studies such as Kim et al, (2015); Zhang et al. (2008) among others have reported a quantitative relationship between exposure to high concentrations of small particulates $\left(\mathrm{PM}_{10}\right.$ and $\mathrm{PM}_{2.5}$ ) and increased mortality or morbidity, both daily and over time. Conversely, when concentrations of small and fine particulates are reduced, related mortality will also go down - presuming other factors remain the same. This allows policymakers to project the population health improvements that could be expected if particulate air pollution is reduced.

Health effects of PM was significantly aroused in 2005 and the years that followed spurred by issuance of 2005 global update of the WHO air quality guidelines (WHO Regional Office for Europe, 2006). These studies have provided considerable support for the scientific conclusions in the 2005 global update of the WHO air quality guidelines and suggest additional health outcomes to be associated with PM.

Of important mention is the fact that this 2005 global update of the WHO air quality guideline for PM was based primarily on the findings of prospective cohort studies of Pope et al. (2002) on the effects of long-term exposures on mortality, with support provided by the studies of Dockery et al. (1993) and Jerrett et al. (2005). By extension, if long term exposure to PM as concluded by these studies led to mortality, it follows that some form of morbidity ought to have predisposed the subjects' deaths. 
Additional scientific support for these studies was provided at the time by an independent reanalysis conducted by Krewski et al. (2009) and by a study conducted in Europe (Hoek et al., 2002b). In prospective cohort studies, a sample of individuals are selected and followed over time. For example, Dockery et al. (1993) published results for a 15-year prospective study (the Harvard Six Cities Study) based on approximately 8000 individuals in six cities in the eastern United States. Pope et al. (2002) published results of a prospective study of the mortality experience of approximately 550000 individuals in 151 cities in the United States, using a cohort participating in a long-term investigation sponsored by the American Cancer Society. These studies used individual-level data, so that other factors that affect mortality could be characterized and adjusted in the analysis. Several different cause-specific categories of mortality were examined, including from cardiovascular plus pulmonary and lung cancer.

The Harvard Six Cities Study and the study of the American Cancer Society cohort have been updated several times, with systematic increases in the number of years of analysis and deaths that were followed and in the sophistication of the statistical methodology (Laden et al., 2006; Lepeule et al., 2012; Krewski et al., 2009). These reanalyses continue to find a consistent, statistically significant association between long-term exposure to PM and the risk of mortality. In addition, the magnitude of the effect estimate (that is, the mortality effect per unit of exposure) remains consistent with that of the original study.

In a large Canadian study, associations persisted at very low concentrations (Crouse et al., 2012). Specifically, the effects of long-term exposure on mortality have been reported for several new cohorts (Filleul et al., 2005; Miller et al., 2007; Beelen et al., 2008a; Puett et al., 2009; Ostro et al., 2010; Lipsett et al., 2011; Crouse et al., 2012). Some cohort studies have found no associations between PM and mortality (Puett et al., 2011; Ueda et al., 2012), but these do not materially affect the overall assessment and conclusions.

Regarding the European studies, the mortality risk estimated in the Dutch mortality cohort study for PM was $6 \%$ per $10 \mu \mathrm{g} / \mathrm{m} 3$ for natural-cause mortality (Beelen et al., 2008a), identical to the estimate from the American Cancer Society study (Pope et al., 2002). Furthermore, a large ecological study from Norway reported significant associations between PM2.5 and cardiorespiratory mortality (Naess et al., 2007).

Birth cohort studies in Europe and elsewhere published since 2005 have reported significant associations between exposure to PM and respiratory infections and asthma in young children (Brauer et al., 2007; Gehring et al., 2010; MacIntyre et al., 2014;). Several studies have found an association between PM and infant bronchiolitis, an important risk for hospitalization (Karr et al., 2009).

One of the measures of morbidity used across studies is hospital admission. A recent study from Stockholm reported associations of daily mortality and admissions with PM (Meister, Johansson \& Forsberg, 2012). A study in Barcelona also found a significant association between daily mortality and PM, which was further shown to differ for particles from different sources (Ostro et al., 2010). New evidence of effects on hospital admissions was based on PM in Europe (Brook et al., 2010). 
Additional epidemiologic studies evaluated in the 2009 PM ISA (2009) examined associations between short-term PM exposure and respiratory hospital admissions and ED visits. This limited number of studies demonstrated consistent positive associations with respiratory-related hospital admissions and ED visits with the strongest evidence in children. The evidence from these studies in combination with the evidence from toxicological and controlled human exposure studies led to the conclusion that the collective evidence across disciplines is suggestive of a causal relationship between short-term exposures to PM10-2.5 and respiratory effects. One realisation that arises from these findings is that children are a vulnerable group in suffering exposure in developed countries. Yet in rural third world communities where poverty is the main source of vulnerability, this may not necessarily be the case.

In the US a number of studies published multicity or multi-location analyses to examine the association between short-term exposures and respiratory hospital admissions. Bell et al. (2012) represented a consolidated and more detailed account of a number of previous publications, (Bell et al., 2009a; Bell et al., 2009b; Bell et al., 2008). In an all-year analysis of 187 U.S. counties, short-term exposure to PM was positively associated with respiratory hospital admissions in individuals 65 years of age and older, with the strongest association at $(0.41 \%$ [95\% CI: $0.09,0.74])$. This is interpreted to mean that at $95 \%$ confidence interval, there is a $41 \%$ chance that a person aged 65 or older will be admitted to hospital after exposure which is quite high percentage.

Stieb at al. (2009) conducted a study in 7 Canadian cities to examine the effect of air pollution on ED visits for multiple respiratory-related health outcomes including asthma, COPD, and respiratory infection. The authors found no evidence of an association between short-term PM exposure and COPD ED visits at any of the single-day lags examined. In all-year analyses, positive associations were observed for asthma with the magnitude of the association increased (i.e., the strongest association was observed at lag 0, 2.1\% [95\% CI: $-3.0,7.5]$ ). However, in a warm season analysis (April-September), the magnitude of the association between PM2.5 and asthma was nearly 4 times higher (9.3\% [95\% CI: 6.3, 12.5]).

Fewer studies have been undertaken in developing countries, not because pollution is not an affliction but because there are perceptions that more pertinent issues to due dealt with such as food security, general health conditions, unemployment and poverty. Yet evidence continues to indicate that air pollution is just as lethal if not acutely adverse in developing nations.

For instance, as study carried out in Bangladesh by Utahh (2010) found out that respiratory disorder was highlighted as a major problem in 11 Focus Group Discussions and participants in Bagambar village also mentioned the problem of asthma. Although this may be caused by a number of factors studies have shown that occasional high concentrations of hydrogen sulphide found in community air samples were consistent with complaints of headaches, eye irritation, and sore throats (Fielder et al., 2005).

From the above review, this study can deduce that methodologies are varied some comprising of cohort, epidemiology, toxicology, population and even biological studies. However, the 
findings go a long way to confirms that there are grave negative effects of exposure to PM irrespective of demographic characteristics of population studied. The studies have also gone ahead to reveal that lowered exposure levels are significant even to the point of increasing life expectancy which is remarkable.

Conversely while the studies reviewed provide adequate and remarkable contributions to the effects of PM on morbidity, all of them are drawn from developed world with proper and enforced ambient air quality standards, a serious point of departure from what this study encountered. On the other hand, source pollutants are not localised to single source pollutants as most of them were set in cities like would be the case of a pulp and paper mill. Consequently, this study hoped to fill this gaps.

\section{Methodology}

In determining the association between emissions concentration and human health the study applied $\mathrm{PM}_{10}$ as a proxy for concentrations as estimated in Kiano et al (2017) while health effects sought were respiratory illnesses and symptoms which the study respondents would easily identify with even without diagnosis by a medical practitioner. Correlational research design was adopted as seen in the studies by Hoek et al (2013) among others.

In addition, observational population-based cohort study was conducted. Two cohorts or groups of respondents were selected. One with emission exposure and the other without (from the control site-kakamega). The cohort comprised of households' heads residents of the study sites. Quarterly visits were made to the same households in which episodes of respiratory symptoms or illness suffered within the quarter were recorded for the period between February 2007 and January 2009. This derived the exposure-response function of particulate matter and respiratory illness for the study area as a test of hypothesis that there is no association between pollutant exposure and respiratory illness and by extension health effect. This methodology is consistent with studies done by Caseroni et al (2013) among others.

Prevalence of respiratory condition was given as a percentage of persons interviewed either in the study site or control site. The study modelled the relationship between exposure and various morbidity effects using logistic regression. Odds ratio (OR) was computed $\alpha=5 \%$. According to Szumilas (2010) an odds ratio (OR) is a measure of association between an exposure and an outcome. The OR represents the odds that an outcome will occur given a particular exposure level, compared to the odds of the outcome occurring in the absence of that exposure. Based on logistic regression modelled, the regression coefficient (b1) is the estimated increase in the log odds of the outcome per unit increase in the value of the exposure.

Odds ratios were used to compare the relative odds of the occurrence of the outcome of interest. In which case when $\mathrm{OR}=1$ Exposure does not affect odds of outcome; when $\mathrm{OR}>1$ Exposure associated with higher odds of outcome and when $\mathrm{OR}<1$ Exposure associated with lower odds of outcome. For the purpose of hypothesis testing an alpha of 5\% $(\alpha=0.05)$, in which case in instances where $\mathrm{p}$ values exceeded alpha, the relationship was considered 


\section{Macrothink}

Environmental Management and Sustainable Development

ISSN 2164-7682

2018, Vol. 7, No. 2

insignificant hence accepting the null hypothesis. The $95 \%$ confidence interval (CI) is used to estimate the precision of the OR.

\section{Results and Discussion}

\subsection{Demographic Characteristics of Respondents}

The study collected data from Kakamega (Control) and Webuye over a period of twenty four months within quarterly intervals. A time series prevalence study was achieved as explained in chapter three. Demographic characteristics of persons surveyed were highlighted as gender, age, level of education, position in household (whether head or not), length of time at site, work environment and smoking habits. These findings are presented in table 1 below.

The survey targeted adults only hence the median age of 37.8 years and 32.4 years for the control and Webuye respectively. The literacy levels of the persons surveyed were fairly high given a cumulative percentage of $75 \%$ for the control and $66 \%$ for Webuye had attended high school and above. The study managed 54\% and 55\% of household heads respectively. Notable though, the larger proportion of respondents in Webuye had lived there for duration of two to five years as compared to the control which depicted a stable trend in population movement over the years. Respondents indicated that most of their productive time was spent outdoors in both instances while a paltry $0.31 \%$ for Control and $0.21 \%$ for Webuye were smokers.

Table 1. Demographic characteristics of respondents

\begin{tabular}{|l|l|l|l|}
\hline \multirow{2}{*}{ Characteristics } & \multicolumn{3}{|l|}{ Emission period } \\
\cline { 2 - 4 } & Control $(\mathrm{n}=560)$ & Webuye $(\mathrm{n}=584)$ & $p$ value \\
\hline Gender & & & \\
\hline Male & 55 & 59 & $\mathrm{n} / \mathrm{s}$ \\
\hline Female & 45 & 41 & $\mathrm{n} / \mathrm{s}$ \\
\hline Median age & 37.8 & 32.4 & $\mathrm{n} / \mathrm{s}$ \\
\hline Education level & & & \\
\hline Elementary & 4 & 8 & $<0.05$ \\
\hline Primary & 21 & 26 & $<0.05$ \\
\hline Secondary & 29 & 51 & $<0.05$ \\
\hline Mid-level College & 37 & 11 & $<0.05$ \\
\hline University & 9 & 4 & $<0.05$ \\
\hline Year lived at site & 18 & & \\
\hline 2-5 years & 39 & 52 & $<0.05$ \\
\hline 5-10years & 43 & 29 & $<0.05$ \\
\hline Above 10years & 23 & 19 & $<0.05$ \\
\hline Work Environment & 77 & 19 & $\mathrm{n} / \mathrm{s}$ \\
\hline Indoor & 0.31 & 81 & $\mathrm{n} / \mathrm{s}$ \\
\hline Outdoor & 0.21 & \\
\hline Smoking Habits & & \\
\hline
\end{tabular}




\section{Macrothink}

Susceptibility to air pollution exposure varies greatly among individuals. Individual risk is determined by genetics, age, nutritional state, presence and severity of respiratory and cardiac conditions, and the use of medications. The variability in the estimates found in epidemiological studies may reflect these differences in the populations studied. Age is an important factor as well, with preadolescents (<13 years) and the elderly ( $>65)$ at greatest risk (Wilson and Spengler 1996, Ghio and others 1999). Since preadolescents were precluded from the study, the susceptibility of this group could also be assured. On the other hand, median ages depicted by the data ported a situation where upper bound extreme cases (elderly) may have been omitted.

Work environment and smoking habits of respondents are other factors which also affect exposure outcomes. Exposure is more severe (WHO, 2002) if the respondents spends more time in outdoors as observed in the study. Smoking occasions its fair share of disease burden making it a strong confounder in pollution exposure studies. In our case the small percentage of smoking respondents is insignificant.

Demographic characteristics across the two sites must be compared for validity and reliability. The study hence determined the statistical significance of both sites given $\alpha=0.05$. Corresponding $\mathrm{p}$ values are computed as shown in table 4.11. Significance difference was noted in the case of education levels and length of time lived at site. In all other instances the differences between the demographic characteristics of Control and Webuye were not significant $(\mathrm{n} / \mathrm{s})$, meaning that the two sites share similar characteristics for the purpose of a prevalence study.

\subsection{Prevalence of Respiratory Infections}

Monto (2004) and Denny Jr (1995) have concluded that respiratory tract illnesses are the most frequent illnesses of humans. This study distinguished symptoms indicating Lower respiratory tract infections (LRTI) presented in table 2 and Upper respiratory tract infections (URTI) presented in table 3 the prevalence of which was determined in each case. Regarding LRTI the study found out that the most prevalent symptom was a persistent cough since it presented in $65.7 \%$ of the respondents in Webuye when emissions were present. This was in sharp contrast with the control site whose prevalence was $12.8 \%$. Generally, prevalence of LRTI symptoms measured when emission was present are quite high with thick mucus, breathlessness, chest pain and infection of airways.

Table 2. Prevalence of Lower respiratory tract infections

\begin{tabular}{|l|l|l|}
\hline Symptoms & Control $(\mathbf{n = 5 6 0})$ & Webuye $(\mathbf{n = 5 8 4})$ \\
\hline Persistent cough & 12.8 & 65.7 \\
\hline Coughing up yellow or green phlegm (thick mucus) & 9.8 & 23.6 \\
\hline Breathlessness & 10.1 & 46.3 \\
\hline Wheezing & 17.3 & 36.9 \\
\hline High temperature (fever) & 20.2 & 48 \\
\hline Chest pain or tightness & 8.8 & 57.9 \\
\hline Infection of the airways (Bronchitis ) & 6.4 & 41.8 \\
\hline
\end{tabular}


In case of respiratory tract infections (URTI), the study found that runny nose, and sneezing were most prevalent symptoms of URTI the scores being $65.9 \%$ and $61.1 \%$ respectively in Webuye. Other symptoms observed were common cold, flu, inflection of voice box, and infection of back of the throat in order of pre-eminence. Sore throat however was least common at $28.3 \%$. These prevalence rates are far much higher than what has been observed for the control site. In which case the study conjectures a direct link between the occurrence of these symptoms and air pollution in Webuye.

The study thus found that most prevalent LRTI symptom was a persistent cough since it presented in about seven in every ten respondents in Webuye when emissions were present. This is in sharp contrast with the control site whose prevalence was observed at about one in every ten respondents. Though majority of studies measure prevalence as incidence of hospital admission with main concentration being on highly susceptible such children and elderly, this study aligns with the findings of Darrow et al (2014) among others especially in respect to prevalence of infection of the airways, wheezing and breathlessness. This study also reinforces the fact that respiratory infections are increasingly becoming a severe risk factor in global burden of disease (Lancet, 2013)

In regard to Upper respiratory tract infections (URTI) The study found that runny nose, and sneezing were most prevalent symptoms of URTI the scores being about $65 \%$ and $61 \%$ respectively in Webuye during emission. Other symptoms observed were common cold, flu, inflection of voice box, and infection of back of the throat in order of pre-eminence. Sore throat however was least common at about 3 in every ten respondents. These prevalence rates were found to be far much higher than what has been observed for the control site.

The findings of this study are in tandem with conclusions by Gwaltney et al (1966); Mbonye (2004); Nokes et al (2008) and Cotton (2008) who found symptoms of flu, sneezing and runny nose to be present among about $70 \%$ of children population and about $40 \%$ among adult populations in given prevailing severe weather conditions in different regions across the globe. In which case pollution is assumed to have the same effects as severe weather conditions such as gale winds, dust storms, tornadoes and tropical cyclones.

Table 3. Prevalence of Upper respiratory tract infections

\begin{tabular}{|l|l|l|}
\hline Symptoms & Control $(\mathbf{n = 5 6 0})$ & Webuye $(\mathbf{n = 5 8 4})$ \\
\hline Common cold & 20.5 & 48.3 \\
\hline Sore throat & 17.8 & 28.3 \\
\hline Sneezing & 22.1 & 61.1 \\
\hline Runny nose & 19.3 & 65.9 \\
\hline Flu & 20.2 & 46.3 \\
\hline Infection of the tonsils and tissues at the back of the throat & 11.3 & 42.1 \\
\hline Infection of the sinuses & 5.2 & 37.7 \\
\hline Infection of the larynx (voice box) & 6.4 & 43.4 \\
\hline
\end{tabular}

When association between PM10 concentration and prevalence of respiratory symptoms were sought, the study found positive association between PM10 concentration and prevalence of 
respiratory symptoms among all symptoms considered in the study. The study finds that a marginal increase of PM10 occasions a 12\% increase in persistent cough prevalence. In the same vain, common cold increased by $92 \%$ while wheezing increased by $22 \%$ all factors remaining constant. These findings are fairly telling yet they do not significantly depart from findings by Patel et al (2010); Beckham et al (2005); Youssouf et al (2014) and Karakatsani (2012).

The odds ratio and accompanying confidence interval of contracting a common cold given a level of PM10 concentration is 2.11(0.27464-1.57216). This means that a person in this environment is two times more likely to contract common cold that in the absence of exposure. Similar observations can be drawn regarding findings in this section. In addition, since in all cases, the $\mathrm{p}$ values determined are less than $\alpha=0.05$, then the study finds that the positive association is significant. In some cases, the study finds that odds ratios are much higher compared to ranges of less than 2 times reported by Beelen et al (2008); Rich et al (2005); Patel et al (2010); and Karakatsani (2012) for respiratory illnesses.

However higher odds seen in regards to common cold, infection of tonsils, sinuses and larynx have been observed in studies by Wong et al (2010) who found the odds of contracting respiratory illness in Wuhan city in China to be 3.68 times given PM10 concentration which again is similar to the odds of contracting a respiratory illness for a smoker subject to findings by Filleul, et al (2005). This goes to show the dire condition of pollution in Webuye and its environs given pollution emission by the mill.

To determine the morbidity health effects of single source industrial pollution, the study performed a logistic regression exposure to pollutant and prevalence of various symptoms such as LRTI and URTI. Though there were several pollutants considered in this study, it is Particulate matter (PM10) that was considered since among others, WHO (2004) has emphasised that prevalent symptoms arising out of exposure to PM10 are either LRTI or URTI, and this empirical evidence is available for comparison. In addition, the relationship between exposure and prevalence was only feasible at the time when the mill was operational thus between January 2007 to February 2009. As such findings presented below relate to that period only since in the subsequent study period no emissions were observed.

The study modelled the relationship between exposure to Particulate matter (PM10) being the independent and respiratory symptoms being dependent variables measured as Sinusitis, Running or stuffy nose, sore throat, Sneezing, Common cold and fever among others. Odds ratio (OR) was computed with $\alpha=5 \%$ and $95 \%$ confidence intervals to estimate the precision of the odds ratio. The results are shown in table 4 below.

The study also modelled the relationship between exposure to Particulate matter (PM10) and prevalence of respiratory symptoms. Respiratory symptoms of interest were those associated with either lower or upper respiratory tract infection as described in the sections above. They include dry cough, cough with phlegm, wheezing, breathlessness on exertion, chest discomfort and sleep disturbance due to breathing problems. Odds ratio (OR) was computed with $\alpha=5 \%$ and $95 \%$ confidence intervals to estimate the precision of the odds ratio. The results are shown in table 4.4 below. 


\section{Macrothink}

Environmental Management and Sustainable Development

ISSN 2164-7682

2018, Vol. 7, No. 2

Table 4. Logistic regression analysis of the association between particulate air pollution $\left(\mathrm{PM}_{10}\right)$ and prevalence of respiratory symptoms

\begin{tabular}{|c|c|c|c|c|c|c|}
\hline Respiratory symptom & Odds Ratio & Co-eff & $\mathrm{z}$ & Std. error & $\mathrm{P}>|\mathrm{z}|$ & $\begin{array}{l}\text { [95\% Conf. } \\
\text { Interval] }\end{array}$ \\
\hline persistent cough & 1.13248 & 0.124 & 0.032 & 3.876 & 0.000 & $\begin{array}{l}(0.061494- \\
0.187326)\end{array}$ \\
\hline $\begin{array}{l}\text { Coughing up yellow or } \\
\text { green phlegm (thick mucus) }\end{array}$ & 1.021528 & 0.0213 & 0.0441 & 0.483 & 0.000 & $\begin{array}{l}(-0.06514 \\
0.107736)\end{array}$ \\
\hline breathlessness & 1.004139 & 0.00413 & 0.002 & 2.065 & 0.003 & $\begin{array}{l}(0.00021 \\
0.00805)\end{array}$ \\
\hline Wheezing & 1.247323 & 0.221 & 0.029 & 7.621 & 0.000 & $\begin{array}{l}(0.16416 \\
-0.27784)\end{array}$ \\
\hline High temperature (fever) & 1.364529 & 2.124 & 1.4231 & 1.493 & 0.000 & $\begin{array}{l}(-0.66528- \\
4.913276)\end{array}$ \\
\hline chest pain or tightness & 1.02062 & 0.02041 & 0.00541 & 3.773 & 0.000 & $\begin{array}{l}0.009806 \\
0.031014\end{array}$ \\
\hline $\begin{array}{l}\text { Infection of the airways } \\
\text { (Bronchitis ) }\end{array}$ & 1.407197 & 0.3416 & 0.192 & 1.779 & 0.006 & $\begin{array}{l}-0.03472 \\
0.71792\end{array}$ \\
\hline common cold & 2.517836 & 0.9234 & 0.331 & 2.790 & 0.000 & $\begin{array}{l}0.27464 \\
1.57216\end{array}$ \\
\hline sore throat & 1.652187 & 0.5021 & 0.14201 & 3.536 & 0.0042 & $\begin{array}{l}0.22376 \\
0.78044\end{array}$ \\
\hline Sneezing & 1.393474 & 0.3318 & 0.321 & 1.034 & 0.000 & $\begin{array}{l}-0.29736 \\
0.96096\end{array}$ \\
\hline runny nose & 1.524856 & 0.4219 & 0.1498 & 2.816 & 0.000 & $\begin{array}{l}0.128292 \\
0.715508\end{array}$ \\
\hline flu & 1.053703 & 0.052311 & 0.0214 & 2.444 & 0.000 & $\begin{array}{l}0.010367 \\
0.094255\end{array}$ \\
\hline $\begin{array}{l}\text { infection of the tonsils and } \\
\text { tissues at the back of the throat }\end{array}$ & 4.272076 & 1.4521 & 0.3299 & 4.402 & 0.000 & $\begin{array}{l}0.805496 \\
2.098704\end{array}$ \\
\hline infection of the sinuses & 2.826672 & 1.0391 & 0.3091 & 3.362 & 0.005 & $\begin{array}{l}0.433264 \\
1.644936 \\
\end{array}$ \\
\hline $\begin{array}{l}\text { infection of the larynx } \\
\text { (voice box) }\end{array}$ & 4.768348 & 1.562 & 0.4205 & 3.715 & 0.001 & $\begin{array}{l}0.73782 \\
2.38618\end{array}$ \\
\hline
\end{tabular}

In all instances, the data presented in table 4 above finds positive association between PM10 concentration and prevalence of respiratory symptoms. The study finds that a marginal increase of PM10 occasions a 12\% increase in persistent cough prevalence. In the same vain, common cold increased by $92 \%$ while wheezing increased by $22 \%$ all factors remaining constant. These findings are fairly telling yet they do not significantly depart from findings by Patel et al (2010); Lin et al (2005); Youssouf et al (2014) and Karakatsani (2012).

The odds ratio and accompanying confidence interval of contracting a common cold given a 
level of PM10 concentration is 2.11(0.27464-1.57216). This means that a person in this environment is two times more likely to contract common cold that in the absence of exposure. Similar observations can be drawn regarding findings in this section. In addition, since in all cases, the $p$ values determined are less than $\alpha=0.05$, then the study finds that the positive association is significant. In some cases, the study finds that odds ratios are much higher compared to ranges of less than 2 times reported by Beelen et al (2008); Rich et al (2005); Patel et al (2010); and Karakatsani (2012) for respiratory illnesses. However higher odds seen in regards to common cold, infection of tonsils, sinuses and larynx have been observed in studies by Wong et al (2010) who found the odds of contracting respiratory illness in Wuhan city in China to be 3.68 times given PM10 concentration which again is similar to the odds of contracting a respiratory illness for a smoker subject to findings by Filleul (2004). This goes to show the dire condition of pollution in Webuye and its environs given pollution emission by the mill.

\section{Conclusions}

The study also set to establish the pollution exposure effects on health during the emission period. In this regard, the study concludes that Webuye environs exhibits high prevalence of respiratory diseases as compared to the control site. Specifically, about 6 out of 10 respondents suffered Upper Respiratory tract infection (URTI) or Lower Respiratory tract infection (LRTI). Further, the study concludes that there is a significant difference between LRTI symptoms such as thick mucus, chest pain and fever between the emission and the post emission periods of the study. However, insignificant difference is observed on URTI symptoms such as common cold, sneezing and sore throat. Regarding morbidity effect of ambient air pollution, the study concludes that there is a positive significant relationship between chronic exposure to $\mathrm{PM}_{10}$ and respiratory symptoms.

\section{References}

Ayres, Jon G., Paul Borm, Flemming R. Cassee, Vincent Castranova, Ken Donaldson, Andy Ghio, Roy M. Harrison et al. (2008). Evaluating the toxicity of airborne particulate matter and nanoparticles by measuring oxidative stress potential-a workshop report and consensus statement. Inhalation toxicology, 20(1), 75-99. https://doi.org/10.1080/08958370701665517

Beckham, J. D., Cadena, A., Lin, J., Piedra, P. A., Glezen, W. P., Greenberg, S. B., \& Atmar, R. L. (2005). Respiratory viral infections in patients with chronic, obstructive pulmonary disease. Journal of Infection, 50(4), 322-330. https://doi.org/10.1016/j.jinf.2004.07.011

Beelen, R., Hoek, G., van Den Brandt, P. A., Goldbohm, R. A., Fischer, P., Schouten, L. J., ... \& Brunekreef, B. (2008). Long-term effects of traffic-related air pollution on mortality in a Dutch cohort (NLCS-AIR study). Environmental health perspectives, 116(2), 196. https://doi.org/10.1289/ehp.10767

Bell, M. L., \& Ebisu, K. (2012). Environmental inequality in exposures to airborne particulate matter components in the United States. Environmental health perspectives, 120(12), 1699. https://doi.org 10.1289/ehp.1205201 
Bhambhani, Y., \& Singh, M. (1985). Ventilatory thresholds during a graded exercise test. Respiration, 47(2), 120-128. https://doi.org/10.1159/000194758

Brauer, M., Hoek, G., Smit, H. A., De Jongste, J. C., Gerritsen, J., Postma, D. S., ... Brunekreef, B. (2007). Air pollution and development of asthma, allergy and infections in a birth cohort. European Respiratory Journal, 29(5),

https://doi.org/879-888/10.1183/09031936.00083406

Brasseur, P., Gruber, N., Barciela, R., Brander, K., Doron, M., Elmoussaoui, A., ... Matear, R. (2009). Integrating biogeochemistry and ecology into ocean data assimilation systems. Oceanography, 22(3), 206-215.

Brook, R. D., Rajagopalan, S., Pope, C. A., Brook, J. R., Bhatnagar, A., Diez-Roux, A. V., ... Peters, A. (2010). Particulate matter air pollution and cardiovascular disease. Circulation, 121(21), 2331-2378. https://doi.org/10.1161/CIR.0b013e3181dbece1

Brunekreef, B., \& Holgate, S. T. (2002). Air pollution and health. The lancet, 360(9341), 1233-1242. https://doi.org/10.1016/S0140-6736(02)11274-8

Carlsen, H. K. (2014). Health effects of air pollution in Iceland: respiratory health in volcanic environments (Doctoral dissertation, Umeå universitet).

http://hdl.handle.net/1946/19945

Cesaroni, G., Badaloni, C., Gariazzo, C., Stafoggia, M., Sozzi, R., Davoli, M., \& Forastiere, F. (2013). Long-term exposure to urban air pollution and mortality in a cohort of more than a million adults in Rome. Environmental health perspectives, 121(3), 324.

https://doi.org/10.1289/ehp.1205862

Cotton, M. F., Innes, S., Jaspan, H., Madide, A., \& Rabie, H. (2008). Management of upper respiratory tract infections in children: clinical. Professional Nursing Today, 12(2), 39-44. http://hdl.handle.net/10520/EJC79186

Crouse, D. L., Peters, P. A., van Donkelaar, A., Goldberg, M. S., Villeneuve, P. J., Brion, O., ... Brauer, M. (2012). Risk of nonaccidental and cardiovascular mortality in relation to long-term exposure to low concentrations of fine particulate matter: a Canadian national-level cohort study. Environmental health perspectives, 120(5), 708.

https://doi.org/10.1289/ehp.1104049

Darrow, L. A., Klein, M., Flanders, W. D., Mulholland, J. A., Tolbert, P. E., \& Strickland, M. J. (2014). Air pollution and acute respiratory infections among children 0-4 years of age: an 18-year time-series study. American journal of epidemiology, 180(10), 968-977.

https://doi.org/10.1093/aje/kwu234

Denny Jr, F. W. (1995). The clinical impact of human respiratory virus infections. American journal of respiratory and critical care medicine, 152(4), S4.

https://doi.org/10.1164/ajrccm/152.4_Pt_2.S4

Dockery, D. W., Pope, C. A., Xu, X., Spengler, J. D., Ware, J. H., Fay, M. E., ... Speizer, F. E. (1993). An association between air pollution and mortality in six US cities. New England 
journal of medicine, 329(24), 1753-1759. https://doi.org/10.1056/NEJM199312093292401

Donaldson, G. C., \& Wedzicha, J. A. (2014). The causes and consequences of seasonal variation in COPD exacerbations. International journal of chronic obstructive pulmonary disease, 9, 1101. https://doi.org/10.2147/COPD.S54475

Egondi, T., Kyobutungi, C., Ng, N., Muindi, K., Oti, S., Vijver, S. V. D., ... Rocklöv, J. (2013). Community perceptions of air pollution and related health risks in Nairobi slums. International journal of environmental research and public health, 10(10), 4851-4868. https://doi.org/10.3390/ijerph10104851

Fiedler, V., Maso, M. D., Boy, M., Aufmhoff, H., Hoffmann, J., Schuck, T., ... Kulmala, M. (2005). The contribution of sulphuric acid to atmospheric particle formation and growth: a comparison between boundary layers in Northern and Central Europe. Atmospheric Chemistry and Physics, 5(7), 1773-1785. https://doi.org/10.5194/acp-5-1773-2005

Filleul, L., Rondeau, V., Vandentorren, S., Le Moual, N., Cantagrel, A., Annesi-Maesano, I., ... Vervloet, D. (2005). Twenty five year mortality and air pollution: results from the French PAARC survey. Occupational and environmental medicine, 62(7), 453-460.

http://dx.doi.org/10.1136/oem.2004.014746

Firket, J. (1936). Fog along the Meuse valley. Transactions of the Faraday Society, 32, 1192-1196.

Gehring, U., Wijga, A. H., Brauer, M., Fischer, P., de Jongste, J. C., Kerkhof, M., ... Brunekreef, B. (2010). Traffic-related air pollution and the development of asthma and allergies during the first 8 years of life. American journal of respiratory and critical care medicine, 181(6), 596-603. https://doi.org/10.1164/rccm.200906-08580C

Gwaltney Jr, J. M., Hendley, J. O., Simon, G., \& Jordan Jr, W. S. (1966). Rhinovirus infections in an industrial population: the occurrence of illness. New England Journal of Medicine, 275(23), 1261-1268. http://dx.doi.org/10.1056/NEJM196612082752301

Hoek, G., Krishnan, R. M., Beelen, R., Peters, A., Ostro, B., Brunekreef, B., \& Kaufman, J. D. (2013). Long-term air pollution exposure and cardio-respiratory mortality: a review. Environmental Health, 12(1), 43. https://doi.org/10.1186/1476-069X-12-43

Jerrett, M., Burnett, R. T., Ma, R., Pope III, C. A., Krewski, D., Newbold, K. B., ... Thun, M. J. (2005). Spatial analysis of air pollution and mortality in Los Angeles. Epidemiology, 16(6), 727-736. https://doi.org/10.1097/01.ede.0000181630.15826.7d

Karakatsani, A., Analitis, A., Perifanou, D., Ayres, J. G., Harrison, R. M., Kotronarou, A., ... de Hartog, J. J. (2012). Particulate matter air pollution and respiratory symptoms in individuals having either asthma or chronic obstructive pulmonary disease: a European multicentre panel study. Environmental Health, 11(1), 75.

https://doi.org/10.1186/1476-069X-11-75

Karakis, I., Kordysh, E., Lahav, T., Bolotin, A., Glazer, Y., Vardi, H., ... Sarov, B. (2009). Life prevalence of upper respiratory tract diseases and asthma among children residing in rural 
area near a regional industrial park: cross-sectional study. Rural Remote Health, 9(3), 1092.

Karr, C. J., Rudra, C. B., Miller, K. A., Gould, T. R., Larson, T., Sathyanarayana, S., \& Koenig, J. Q. (2009). Infant exposure to fine particulate matter and traffic and risk of hospitalization for RSV bronchiolitis in a region with lower ambient air pollution. Environmental research, 109(3), 321-327. https://doi.org/10.1016/j.envres.2008.11.006

Kiano, E. K., Yabann, W. K., \& Sumukwo, J. (2017). Assessing Levels of Ambient Air Quality for Pulp and Paper Milling Industry in Kenya. Journal of Natural Sciences Research, $7(20)$.

Kim, K. H., Kabir, E., \& Kabir, S. (2015). A review on the human health impact of airborne particulate matter. Environment international, 74, 136-143.

https://doi.org/10.1016/j.envint.2014.10.005

Krewski, D., Jerrett, M., Burnett, R. T., Ma, R., Hughes, E., Shi, Y., ... Thun, M. J. (2009). Extended follow-up and spatial analysis of the American Cancer Society study linking particulate air pollution and mortality (No. 140). Boston, MA: Health Effects Institute.

Laden, F., Schwartz, J., Speizer, F. E., \& Dockery, D. W. (2006). Reduction in fine particulate air pollution and mortality: extended follow-up of the Harvard Six Cities study. American journal of respiratory and critical care medicine, 173(6), 667-672.

https://doi.org/10.1164/rccm.200503-443OC

Le, T. G., Ngo, L., Mehta, S., Do, V. D., Thach, T. Q., Vu, X. D., ... Cohen, A. (2012). Effects of short-term exposure to air pollution on hospital admissions of young children for acute lower respiratory infections in Ho Chi Minh City, Vietnam. Research Report (Health Effects Institute), (169), 5-72.

Lepeule, J., Laden, F., Dockery, D., \& Schwartz, J. (2012). Chronic exposure to fine particles and mortality: an extended follow-up of the Harvard Six Cities study from 1974 to 2009. Environmental health perspectives, 120(7), 965.

Lipsett, M. J., Ostro, B. D., Reynolds, P., Goldberg, D., Hertz, A., Jerrett, M., ... \& Bernstein, L. (2011). Long-term exposure to air pollution and cardiorespiratory disease in the California teachers study cohort. American journal of respiratory and critical care medicine, 184(7), 828-835. https://doi.org/10.1289/ehp.1104660

Ljungman, P. L., \& Mittleman, M. A. (2014). Ambient air pollution and stroke. Stroke, 45(12), 3734-3741. https://doi.org/10.1161/STROKEAHA.114.003130

MacIntyre, E. A., Gehring, U., Mölter, A., Fuertes, E., Klümper, C., Krämer, U., ... Koppelman, G. H. (2014). Air pollution and respiratory infections during early childhood: an analysis of 10 European birth cohorts within the ESCAPE Project. Environmental health perspectives, 122(1), 107. https://doi.org/10.1289/ehp.1306755

Mbonye, A. K. (2004). Risk factors for diarrhoea and upper respiratory tract infections among children in a rural area of Uganda. Journal of Health, Population and Nutrition, 52-58. 
Miller, K. A., Siscovick, D. S., Sheppard, L., Shepherd, K., Sullivan, J. H., Anderson, G. L., \& Kaufman, J. D. (2007). Long-term exposure to air pollution and incidence of cardiovascular events in women. $N$ Engl j Med, 2007(356), 447-458.

https://doi.org/10.1056/NEJMoa054409

Monto, A. S. (2004). Occurrence of respiratory virus: time, place and person. The Pediatric infectious disease journal, 23(1), S58-S64.

https://doi.org/10.1097/01.inf.0000108193.91607.34

Nakhlé, M. M., Farah, W., Ziadé, N., Abboud, M., Salameh, D., \& Annesi-Maesano, I. (2015). Short-term relationships between emergency hospital admissions for respiratory and cardiovascular diseases and fine particulate air pollution in Beirut, Lebanon. Environmental monitoring and assessment, 187(4), 196. https://doi.org/10.1007/s 1066

Nokes, D. J., Okiro, E. A., Ngama, M., Ochola, R., White, L. J., Scott, P. D., ... Medley, G. F. (2008). Respiratory syncytial virus infection and disease in infants and young children observed from birth in Kilifi District, Kenya. Clinical infectious diseases, 46(1), 50-57. https://doi.org/10.1086/524019

Olmo, N. R. S., Saldiva, P. H. D. N., Braga, A. L. F., Lin, C. A., Santos, U. D. P., \& Pereira, L. A. A. (2011). A review of low-level air pollution and adverse effects on human health: implications for epidemiological studies and public policy. Clinics, 66(4), 681-690. http://dx.doi.org/10.1590/S1807-59322011000400025

Ostro, B., Lipsett, M., Reynolds, P., Goldberg, D., Hertz, A., Garcia, C., ... \& Bernstein, L. (2010). Long-term exposure to constituents of fine particulate air pollution and mortality: results from the California Teachers Study. Environmental health perspectives, 118(3), 363. http://dx.doi.org/10.1289/ehp.0901181

Patankar, A. M., \& Trivedi, P. L. (2011). Monetary burden of health impacts of air pollution in Mumbai, India: implications for public health policy. Public health, 125(3), 157-164. https://doi.org/10.1016/j.puhe.2010.11.009

Patel, M. M., Chillrud, S. N., Correa, J. C., Hazi, Y., Feinberg, M., Kc, D., ... Kinney, P. L. (2010). Traffic-related particulate matter and acute respiratory symptoms among New York City area adolescents. Environmental health perspectives, 118(9), 1338.

https://doi.org/10.1289/ehp.0901499

Pope III, C. A., Burnett, R. T., Thun, M. J., Calle, E. E., Krewski, D., Ito, K., \& Thurston, G. D. (2002). Lung cancer, cardiopulmonary mortality, and long-term exposure to fine particulate air pollution. Jama, 287(9), 1132-1141. https://doi.org/10.1001/jama.287.9.1132

Pope, C. A., \& Kanner, R. E. (1993). Acute effects of PM10 pollution on pulmonary function of smokers with mild to moderate chronic obstructive pulmonary disease. Am Rev Respir Dis, 147(6 Pt 1), 1336-1340. https://doi.org/10.1164/ajrccm/147.6_Pt_1.1336

Puett, R. C., Hart, J. E., Yanosky, J. D., Paciorek, C., Schwartz, J., Suh, H., ... Laden, F. (2009). Chronic fine and coarse particulate exposure, mortality, and coronary heart disease in 
the Nurses' Health Study. Environmental health perspectives, 117(11), 1697. https://doi.org/10.1289/ehp.0900572

Rich, D. Q., Schwartz, J., Mittleman, M. A., Link, M., Luttmann-Gibson, H., Catalano, P. J., ... Dockery, D. W. (2005). Association of short-term ambient air pollution concentrations and ventricular arrhythmias. American Journal of Epidemiology, 161(12), 1123-1132. https://doi.org/10.1093/aje/kwi143

Ristovski, Z. D., Miljevic, B., Surawski, N. C., Morawska, L., Fong, K. M., Goh, F., \& Yang, I. A. (2012). Respiratory health effects of diesel particulate matter. Respirology, 17(2), 201-212. https://doi.org/10.1111/j.1440-1843.2011.02109.x

Romieu, I., Gouveia, N., Cifuentes, L. A., de Leon, A. P., Junger, W., Vera, J., ... Carbajal-Arroyo, L. (2012). Multicity study of air pollution and mortality in Latin America (the ESCALA study). Research report (Health Effects Institute), (171), 5-86.

Stieb, D. M., Szyszkowicz, M., Rowe, B. H., \& Leech, J. A. (2009). Air pollution and emergency department visits for cardiac and respiratory conditions: a multi-city time-series analysis. Environmental Health, 8(1), 25. https://doi.org/10.1186/1476-069X-8-25

Szumilas, M. (2010). Explaining odds ratios. Journal of the Canadian Academy of Child and Adolescent Psychiatry, 19(3), 227.

Thurston, G. D., Ito, K., Hayes, C. G., Bates, D. V., \& Lippmann, M. (1994). Respiratory hospital admissions and summertime haze air pollution in Toronto, Ontario: consideration of the role of acid aerosols. Environmental Research, 65(2), 271-290.

https://doi.org/10.1006/enrs.1994.1037

Ueda, Kayo, Atsushi Shimizu, Hiroshi Nitta, and Kenichiro Inoue. (2012). Long-range transported Asian Dust and emergency ambulance dispatches. Inhalation toxicology, 24(12), 858-867. https://doi.org/10.3109/08958378.2012.724729

U.S. EPA. (2004). Air Quality Criteria for Particulate Matter. EPA/600/P-99/002aF-bF. Research Triangle Park, NC: U.S. Environmental Protection Agency.

U.S. EPA. (2006). Aging and Toxic Response: Issues Relevant to Risk Assessment (Final) Washington, DC: U.S. Environmental Protection Agency.

Wong, C. M., Vichit-Vadakan, N., Vajanapoom, N., Ostro, B., Thach, T. Q., Chau, P. Y., ... Peiris, J. S. (2010). Part 5. Public health and air pollution in Asia (PAPA): a combined analysis of four studies of air pollution and mortality. Research report (Health Effects Institute), (154), 377-418.

Wordley, J., Walters, S., \& Ayres, J. G. (1997). Short term variations in hospital admissions and mortality and particulate air pollution. Occupational and environmental medicine, 54(2), 108-116. http://dx.doi.org/10.1136/oem.54.2.108

World Health Organization (WHO. (2000). Air quality guidelines for Europe.

World Health Organization, \& UNAIDS. (2006). Air quality guidelines: global update 2005. 
World Health Organization.

World Health Organization. (2005). Effects of air pollution on children's health and development: a review of the evidence.

Youssouf, H., Liousse, C., Roblou, L., Assamoi, E. M., Salonen, R. O., Maesano, C., ... Annesi-Maesano, I. (2014). Quantifying wildfires exposure for investigating health-related effects. Atmospheric environment, 97, 239-251.

https://doi.org/10.1016/j.atmosenv.2014.07.041

Zúñiga, J., Tarajia, M., Herrera, V., Urriola, W., Gómez, B., \& Motta, J. (2016). Assessment of the possible association of air pollutants PM10, O3, NO2 with an increase in cardiovascular, respiratory, and diabetes mortality in Panama City: a 2003 to 2013 data analysis. Medicine, 95(2). https://doi.org/10.1097/MD.0000000000002464

\section{Copyright Disclaimer}

Copyright for this article is retained by the author(s), with first publication rights granted to the journal.

This is an open-access article distributed under the terms and conditions of the Creative Commons Attribution license (http://creativecommons.org/licenses/by/3.0/). 